\title{
The Effect of HIV-Related Knowledge on the Willingnes to Participate in Voluntary Counseling and Testing (VCT) Among Nursing Students
}

\author{
Ni Putu Wulan Purnama Sari ${ }^{1}$ \\ Faculty of Nursing, Widya Mandala Catholic University \\ Surabaya (WMCUS) \\ Surabaya, Indonesia \\ wulanpurnama@ukwms.ac.id
}

\author{
Anselmus Aristo Parut ${ }^{2}$ \\ STIKES Bali; Jl. Tukad Balian No. 180, Renon, Denpasar, \\ Bali, Indonesia \\ arisparut2@gmail.com
}

\begin{abstract}
Introduction: Youth aged 15-24 years old have the high vulnerability to HIV infection. Students who lack parental supervision have more opportunity to try new things including sexual matter. Nursing students frequently provide care for several patients who unaware of their HIV status. These increases the students' HIV susceptibility. This study aims to analyze the effect of HIVrelated knowledge on the willingness to participate in VCT among nursing students. Method: This is a cross-sectional study involving 137 nursing students in a university in Surabaya. Sample chose by random sampling. Instruments used were questionnaires of KQ-18 and general attitude to VCT. Data analysis used regression test with $\alpha \leq 0.05$. Result: Most respondents were females, 20 years old, single, living with parents. They got HIV health education more than twice so far and mostly got information about HIV in the seminar. Most respondents have low HIVrelated knowledge but willing enough to participate in VCT. HIV-related knowledge only influences the willingness to participate in VCT of $0.2 \%$, while the other $\mathbf{9 9 . 8 \%}$ influences are caused by the other unidentified factors. The regression model was not significant $(p=$ 0.632). Conclusion: HIV-related knowledge has a very slight influence on the willingness to participate in VCT among nursing students.
\end{abstract}

Keywords: HIV, VCT, knowledge, willingness, nursing student.

\section{INTRODUCTION}

The young generation of both men and women aged 15-24 years are particularly vulnerable to HIV infection because young people/teenagers are in the experimental phase of everything including in sexual matters [1]. Students are highly vulnerable to HIV infection due to lack of knowledge and lack of parental supervision, especially university students who live far away from their parents, thus giving them more opportunity to try new things, including sex experience [2]. Based on data of basic health research from Ministry of Health (MOH) of Indonesia Republic (RI) in 2012, only $13 \%$ of young/teenage girls and $12 \%$ of young/teenage boys who have a comprehensive knowledge about HIV/AIDS, while the Millennium Development Goals (MDGs) for the knowledge of young people is $95 \%$ [3].

Surveys conducted by $\mathrm{MOH}$ of RI and the Commission of Acquired Immunodeficiency Syndrome (AIDS) of RI in Central Java revealed that nearly $40 \%$ of AIDS cases are found in patients aged 20-29 years, which means that they are infected by the age of 15-24 years (MOH of RI, 2014; Central Java AIDS Commission, 2014). Data of General Directorate of PP and PL (2014) shows that from April $1^{\text {st }}, 1987$ to September $30^{\text {th }}, 2014$, there were 150,296 cases of HIV and 55,799 cases of AIDS, with the number of patients who died from HIV / AIDS amounted to 9,796 people. The number of HIV / AIDS cases in adolescents and young adults aged 15-29 years as many as 20,069 cases. East Java holds the second rank by number as many as 19,249 cases of HIV and 8,976 cases of AIDS [4].

UNAIDS statistics in 2011 revealed that 36.9 million people were living with HIV, 2 million new patients were infected, and 1.2 thousand people died from HIV/AIDS throughout the world. Indonesia still faces a growing HIV epidemic. Data from October to December 2011 reported 5,442 HIV cases and 2,357 AIDS cases. Cumulatively since 1987 up to 2011, there were 21,031 patients with HIV; 7,312 patients with AIDS and 1,139 patients who died from HIV/ AIDS. East Java is at the second position with the number of people infected with HIV as many as 9,950 people and 4,598 people with AIDS, with prevalence rate 12:27/100,000 population. The number of children and adolescents $(<1$ year to 19 years old) who are living with HIV as many as 1,929 people since 1987 up to 2011 [5].

Understanding the mechanism of HIV transmission is the first step in the process of controlling HIV infection. VCT, Initiating Provider Test and Counseling (PITC) and Homebased HIV Counseling and Testing (HBCT) are means by people aware of their HIV status. VCT is one effective method for reducing and controlling the transmission of HIV. VCT is an entry point for patients to get preventive programs, treatment and other comprehensive programs to prevent HIV infection. Research conducted by the World Health Organization revealed that the number of people who 
participate in VCT is very low in countries with high HIV/AIDS cases; it is only $5 \%$ of people living with HIV / AIDS in the world.

WHO interventions focused on several key areas such as testing and counseling which is the entrance to the stage of prevention and treatment [6]. Counseling in VCT is designed to assist patients in interpreting the results of laboratory tests, to change the behavior so new people do not become infected and also prevent transmission from HIV patients to other people [7]. The main target of the Indonesia national strategy for reproductive health and sex education is to increase the knowledge of young people about reproductive health and safe sex in order to promote and facilitate their behavior changes; including increased awareness of respect for others, and the next target is to give young people the knowledge, skills and motivation to behave well, especially related to reproductive health [8]. To achieve the main targets of this national strategy, education on HIV/AIDS should be a compulsory subject or study material for all majors or courses of study in colleges/universities.

Nursing students are the future professional nurses who will give high-quality care to their patients, including HIV-AIDS. In the study process, they will also give nursing care to various patients who are mostly unaware of their HIV status. The high possibility of nursing students to be infected by HIV has made the high importance of HIV-related knowledge since the beginning of their study. Many studies showed that knowledge about HIV correlates with the willingness to participate in VCT. This study aims to analyze the effect of HIV-related knowledge on the willingness to participate in VCT among nursing students.

\section{RESEARCH METHODS}

This study used cross-sectional design and Health Belief Model as the theoretical framework. In the context of this study, researchers conducted a health survey in Faculty of Nursing (FON) of one university in Surabaya. The population was all students of that FON ( $\mathrm{N}=157$, in the academic year of 2016/2017). The sample size was 137 students were chosen by simple random sampling. Sample's inclusion criteria were being the active student in the $2^{\text {nd }}$ semester of the academic year and adult (18-23 years old). The exclusion criteria were rejecting to give signature in the informed consent, incompletely filling the questionnaires, collecting the questionnaires late. Independent variable was HIV-related knowledge while dependent variable was the willingness to participate in VCT.

The instrument of the KQ-18 questionnaire developed by [9] was used for assessing the independent variable: HIV-related knowledge. In the beginning, this instrument consisted of 45 items which developed by Carey, Morrison-Beedy, and Johnson (1977). [9] then choose 18 items from a total of 45 items. This instrument then subsequently named KQ-18. The possible answers were only true, false and no idea. Each true answer was given 5.5 points. The category of HIV-related knowledge was high (score 75100), sufficient (score 50-74.5) and low (score 0-49.5).
Results of the prior study for testing this instrument to 42 nursing students in different university showed only four valid items with $r=-0.333-0.336$ and has a moderate reliability with $\alpha=0.588$. Researchers decided to use the 18 items in this study because the least amount of valid items referred to the lack of knowledge about HIV among nursing students.

The instrument of General Attitudes to VCT was used for assessing the dependent variable: the willingness to participate in VCT. This instrument was modified from similar instruments that were originally developed[7]. At first, this instrument consists of 41 items with Likert scale format. This instrument examines five determinants of attitudes towards HIV testing to be indicative of people willing to take the test, namely: 1) the public and self-perception, 2) the assumption of friends, 3) the value of HIV testing, 4) support and confidentiality, and 5 ) perceived vulnerability. After going through the instrument testing process in Kenya, it is known that there are nine invalid items. This result created a concise form of General Attitudes to VCT questionnaire consisting of 32 items only. The possible answers disagreed (score 1), disagree (score 2), relatively agree (score 3), agree enough (score 4) and strongly agree (score 5). The category of the willingness to participate in VCT was very willing (score 118160), willing enough (score 75-117) and less willing (score 32-74). Results of the prior study for testing this instrument to 42 nursing students in different university showed only 18 items valid with $r=0.295-0.671$ and has high reliability with $\alpha=0.728$. The researcher decided to use the 32 items because the invalid items were still needed to get a general picture of the nursing students' willingness to participate in VCT.

The ethical clearance was issued by the Ethical Committee of Faculty of Nursing, Airlangga University, Indonesia. Other ethical aspects included informed consent, anonymity, and confidentiality. Before filling out the questionnaire, the researchers gave study explanation and asked for respondents' signature in informed consent sheet. The collected data then grouped and analyzed using regression test $(\alpha<0.05)$ to determine the effect of HIV-related knowledge on the willingness to participate in VCT among nursing students.

\section{RESULT}

The study respondents were 137 nursing students.

Table 1 below shows the

\begin{tabular}{ccc}
\hline Characteristic & $\begin{array}{c}\text { Frequency } \\
(\mathbf{n = 1 3 7})\end{array}$ & $\begin{array}{c}\text { Percentage } \\
(\mathbf{\%}) \\
(\mathbf{n = 1 3 7 )}\end{array}$ \\
\hline 1. Age & 11 & \\
a. 18 years old & 26 & 8.03 \\
b. 19 years old & 38 & 18.98 \\
c. 20 years old & 37 & 27.74 \\
d. 21 years old & 17 & 27.01 \\
e. 22 years old & 8 & 12.41 \\
f. 23 years old & & 5.84 \\
2. Gender & 112 & 81.75 \\
a. Female & 25 & 18.25 \\
b. Male & & \\
3. Marital Status & 2 & 1.46 \\
a. Married & 107 & 78.10 \\
b. Single & & \\
\hline
\end{tabular}




\begin{tabular}{|c|c|c|}
\hline c. In a & 28 & 20.44 \\
\hline relationship & & \\
\hline 4. Religion & & \\
\hline a. Hinduism & 3 & 2.19 \\
\hline b. Islam & 40 & 29.20 \\
\hline c. Catholic & 60 & 43.80 \\
\hline d. Christian & 34 & 24.82 \\
\hline 5. Ethnicity & & \\
\hline a. Javanese & 61 & 44.53 \\
\hline b. Chinese & 2 & 1.46 \\
\hline c. Flores & 19 & 13.87 \\
\hline d. Dayak & 7 & 5.11 \\
\hline e. Batak & 4 & 2.92 \\
\hline f. Timor & 7 & 5.11 \\
\hline g. Sumba & 7 & 5.11 \\
\hline h. Ambon & 6 & 4.38 \\
\hline i. Others & 24 & 17.52 \\
\hline 6. Students Level & & \\
\hline a. Freshman & 47 & 34.31 \\
\hline b. $2^{\text {nd }}$ year & 37 & 27.01 \\
\hline c. $3^{\text {rd }}$ year & 27 & 19.71 \\
\hline d. $4^{\text {th }}$ year & 26 & 18.98 \\
\hline 7. High School (HS) & & \\
\hline graduated from & 42 & 30.66 \\
\hline a. HS in & 23 & 16.79 \\
\hline Surabaya & & \\
\hline b. HS in East & & \\
\hline Java & & \\
\hline c. HS in Java & 2 & 1.46 \\
\hline d. HS outside & 70 & 51.09 \\
\hline Java & & \\
\hline 8. Living with & & \\
\hline a. Parents & 52 & 37.96 \\
\hline b. Alone & 38 & 27.74 \\
\hline c. Friends & 20 & 14.59 \\
\hline d. Siblings & 5 & 3.65 \\
\hline e. Spouse & 1 & 0.73 \\
\hline f. Extended & 21 & 15.33 \\
\hline family & & \\
\hline 9. Housing & & \\
\hline Ownership & 49 & 35.77 \\
\hline a. Owner & 1 & 0.73 \\
\hline (parents) & 68 & 49.64 \\
\hline b. Governmental & 19 & 13.87 \\
\hline c. Monthly-rent & & \\
\hline d. Yearly-rent & & \\
\hline 10. Parents' Monthly & & \\
\hline Income (IDR) & 2 & 1.46 \\
\hline a. No income & 6 & 4.38 \\
\hline b. Less than 1 & 91 & 66.42 \\
\hline million & 25 & 18.23 \\
\hline c. $1-3$ million & 13 & 9.49 \\
\hline d. $3-5$ million & & \\
\hline e. More than 5 & & \\
\hline million & & \\
\hline 11. Exposed to & & \\
\hline HIV/AIDS Health & 9 & 6.57 \\
\hline Education & 41 & 29.93 \\
\hline a. Never & 87 & 63.50 \\
\hline b. Once & & \\
\hline c. Twice or more & & \\
\hline 12. Media of & & \\
\hline Information & 10 & 7.30 \\
\hline a. Television & 13 & 9.49 \\
\hline
\end{tabular}

\begin{tabular}{ccc}
\hline b. Book/journal / & 58 & 42.34 \\
printed media & 43 & 32.12 \\
c. Seminar / & 49 & 35.77 \\
workshop & 2 & 1.46 \\
d. Health & 36 & 26.28 \\
education from & 7 & 5.11 \\
healthcare professional & 20 & 14.60 \\
e. College study & 1 & 0.73 \\
material & 2 & 1.46 \\
f. Church & & \\
activity & & \\
g. Social media & & \\
(internet) & & \\
h. Friends & & \\
i. Teacher / & & \\
school & & \\
j. Family & & \\
k. Others & & \\
\hline
\end{tabular}

Table 1 shows that most respondents were females, 20 years old, single, freshman, Catholic, Javanese, high school graduated from outside Java island and still living with parents currently, have gotten HIV health education more than twice so far and got information about HIV mostly from seminar/workshop event.

Table 2. Measured Variables

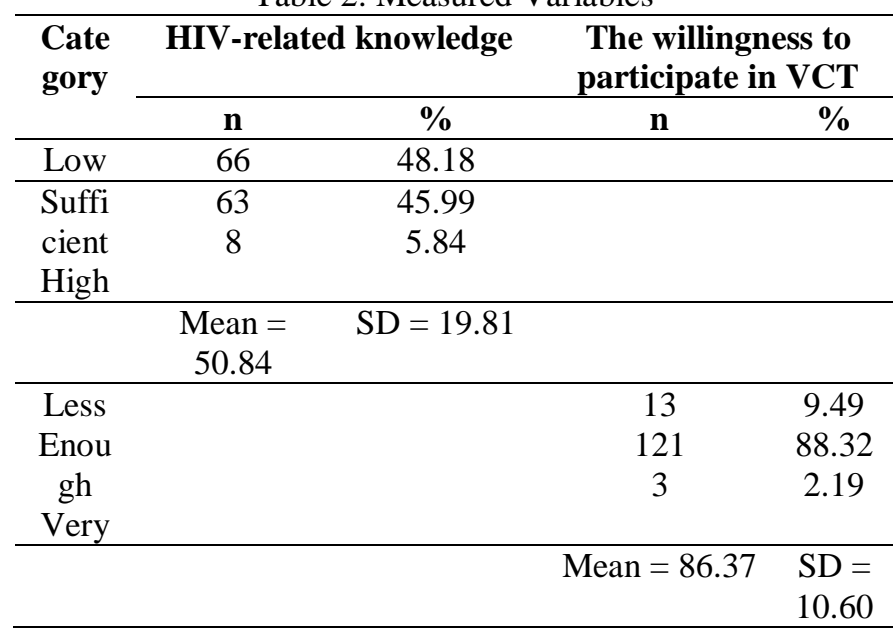

Table 2 shows that most respondents have low HIVrelated knowledge but they were willing enough to participate in VCT. The Mean of HIV-related knowledge was sufficient, while the Mean of the willingness to participate in VCT was enough. The data of the willingness to participate in VCT was more homogenous than the data of HIV-related knowledge because of lower SD.

The statistical test result showed that HIV-related knowledge only influences the willingness to participate in VCT of $0.2 \%$ among nursing students $\left(\mathrm{R}^{2}=0.002\right)$, while the other $99.8 \%$ influences are caused by the other unidentified factors. The regression model was not significant $(p=0.632)$. 


\section{CONCLUSION}

Table 1 showed that most respondents were aged 2021 years old $(54.75 \%)$. Youth aged 15-24 years old are vulnerable to HIV because of the strong influence of peer pressure and the development of their sexual and social identities which often lead to experimentation[7]. The majority of young people in those age group are at risk of HIV infection due to their engagement in unsafe sex, injection drug use, exposure to contaminated blood and blood products or unsterilized skin-piercing procedures. A descriptive study in Kenya proved that age is associated with HIV test uptake[10].

Table 1 showed that most study respondents were females $(81.75 \%)$. Many other studies showed that gender is associated with the willingness to participate in VCT. VCT participants were more likely to be males in Namibia [11]; while men were relatively more likely to get tested for HIV than women through VCT in rural Ethiopia[12]. The study in Kenya showed that there were statistically significant differences between men and women in previous HIV testing status and HIV test uptake. The mean HIV-related knowledge was higher in men than women. Differences were found in expressed HIV stigmatizing attitudes, with women reporting more stigmatizing attitudes than men[10].

Table 1 showed that most respondents were single (78.10\%). Marital status was proved to be associated with VCT participation in Namibia[10]. The basic pattern of behavior change seems to be consistent within marital status. Premarital sex among the unmarried couple and perceived higher severity-vulnerability to HIV among men were associated with willingness to be tested for HIV [13]. Only 2.19\% unmarried respondents have had premarital sex found.

Table 1 showed that study respondents were varied in term of ethnic affiliation and religion. Besides gender, ethnic and religion may affect HIV-related stigma that influences the willingness to participate in VCT. The study in Namibia showed that cultural group was significantly associated with VCT participation; while another study in Burkina Paso showed that Bwaba ethnicity was significantly associated with perceived high personal risk of HIV (Sarker, et al. 2005). Broad cultural norms surrounding gender and HIV-related stigma affect the HIV testing and diagnosisseeking behaviors of members of at-risk marginalized populations (Lofquist, 2012)[14].

Many respondents come from the eastern part of Indonesia. Table 1 showed that $51.09 \%$ respondents finished their basic education outside Java island. A cross-sectional study in rural Ethiopia showed that behavioral and health service factors influence VCT utilization of rural people. Rural people who were better educated and had a comprehensive knowledge with no stigmatization attitude were more likely to undergo VCT. Regional state/province was also strongly associated with VCT utilization in both men and women [12].

Table 1 showed that $37.96 \%$ respondents live with parents. Students are highly vulnerable to HIV infection due to lack of knowledge and lack of parental supervision, especially university students who live far away from their parents, thus giving them more opportunity to try new things, including sex experience [2]. If most study respondents still live with their parents, it could be assumed that they get enough parental supervision.

All nursing students in the place of data collection were unemployed at the moment. Most of their day time was spent on the campus. The main financial supporter was their parents. Individual who belonged to households with higher socioeconomic status and non-farming occupation were more likely to utilize VCT [12]. Table 1 showed that most respondents' parents get the monthly salary of IDR 1-3 million (occupation was unidentified). It is below the Surabaya's minimum wage in 2017 (IDR 3,2 million). Housing status was mostly monthly rent $(49.64 \%)$. It could be assumed that the socioeconomic status or social class of study respondents mostly lower middle. This could influence the accessibility of VCT information and services which lead to fear and HIVrelated stigma.

Table 1 showed that most respondents already got HIV health education twice or more so far $(63.50 \%)$. Seminar/workshop event was shown to be the easiest way to gather HIV knowledge among nursing students (42.34\%). Only $32.12 \%$ respondents got health education from the health care professional. A study in Debre Markos University students, North West Ethiopia (2011), showed that knowledge about HIV, perceived stigma, risk perception, and heard the presence of VCT confidentiality were associated with VCT service utilization among university students. Their major sources of information were mass media and health workers[15]. The information about HIV most likely more effective if disseminated through mass media (printed or electronic) based on [15]than health education activity because of the scope and accessibility among young generation nowadays. The dissemination of information especially on the asymptomatic nature of HIV infection could potentially be very important in forming risk perception, awareness, and the willingness to participate in HIV testing [16].

$\mathrm{VCT}$ is proven to be one of the most powerful weapons in halting the spread of HIV/AIDS. It is known to be a very important component of HIV/AIDS prevention strategies, but various studies have shown the low utilization of VCT service particularly in developing countries[15]. Some studies also have shown that knowledge about HIV often associated with individual willingness to participate in VCT. Table 2 showed that $48.18 \%$ respondents have low HIVrelated knowledge, despite the fact that most of them were exposed to health education about HIV twice or more so far.

Table 2 showed that only $2.19 \%$ respondents showed their strong willingness to participate in VCT. This might be due to lack of knowledge (as shown in Table 1), the fear of HIV testing (expressed) and the possibility of HIV-related stigma. Students who have knowledge about HIV were 3.69 times more likely to utilize VCT service as compared to those who did not have knowledge about HIV[15]. A study in KwaZulu-Natal, South Africa, showed that despite knowledge of HIV, a significant number of patients referred for VCT do not test for HIV in the end [17]. 
The statistical result showed that HIV-related knowledge slightly affects the willingness to participate in VCT among nursing students $\left(\mathrm{R}^{2}=0.002\right.$; means $0.02 \%$ influence). A cross-sectional study in Northeast China supports these study findings. It is showed that greater knowledge of HIV transmission misconceptions and the awareness that apparently healthy person can be an HIV carrier were significantly associated with greater willingness to participate in free HIV testing[18]. A descriptive study utilized data from the 2009/2010 Kenya Demographic Health Survey also showed that HIV-related knowledge, knowledge of someone infected with HIV/AIDS, education attainment were positively associated with HIV test uptake and HIVrelated stigma [10]. Stigma is possibly being a key factor which was not identified in this study.

\section{REFERENCES}

[1] R. Jessor, N. Perspectives, and A. R. Behavior, "A research agenda for adolescent risk-taking: where do we go from here?," pp. 371-376, 2000.

[2] Y. Shiferaw, A. Alemu, A. Assefa, B. Tesfaye, E. Gibermedhin, and M. Amare, "Perception of risk of HIV and sexual risk behaviors among University students: implication for planning interventions," 2014.

[3] A. R. Health, "Demographic and Health Survey:," 2012.

[4] M. Of, H. Republic, and O. F. Indonesia, No Title. .

[5] S. K. Hiv, I. Dilapor, I. Reported, D. K. I. Jakarta, and D. K. I. Jakarta, "Statistik Kasus HIV/AIDS di Indonesia Dilapor s/d Desember 2011 Cases of HIV/AIDS in Indonesia Reported thru' December 2011," no. December, pp. 1-3, 2011.

[6] A. Prevention, "INVESTING IN A COMPREHENSIVE HEALTH SECTOR RESPONSE TO HIV / AIDS Scaling up Treatment and Accelerating Prevention," no. December, 2005.

[7] UNAIDS Report on the global AIDS epidemic | 2012. 2012.

[8] R. Period, "Republic of Indonesia Country Report on the Follow up to the Declaration of Commitment On HIV / AIDS ( UNGASS ), 2009.
[9] A. Manuscript and K. Questionnaire, "Knowledge Questionnaire," vol. 14, no. 2, pp. 172-182, 2008.

[10] G. C. T. Mugoya, "SOCIAL AND COGNITIVE FACTORS ASSOCIATED WITH HIV / AIDS TEST UPTAKE IN KENYA by A Dissertation Submitted to the Faculty of the DEPARTMENT OF DISABILITY AND PSYCHOEDUCATIONAL STUDIES In Partial Fulfillment of the Requirements For the Degree of In the Graduate College THE UNIVERSITY OF ARIZONA," 2012.

[11] "No Title," no. November, 2006.

[12] H. D. Teklehaimanot, A. Teklehaimanot, M. Yohannes, and D. Biratu, "Factors influencing the uptake of voluntary HIV counseling and testing in rural Ethiopia : a cross sectional study," BMC Public Health, pp. 1-13, 2016.

[13] B. Wang, Æ. X. Li, and Æ. B. Stanton, "Correlates of HIV / STD Testing and Willingness to Test among Rural-to-Urban Migrants in China," pp. 891-903, 2010.

[14] D. Lofquist, "HIV TESTING BEHAVIORS OF ATRISK POPULATIONS IN KENYA,” 2012.

[15] G. Tsegay, M. Edris, and S. Meseret, "Assessment of voluntary counseling and testing service utilization and associated factors among Debre Markos University Students, North West Ethiopia : a crosssectional survey in 2011," 2013.

[16] M. Sarker et al., "The Role of HIV-Related Knowledge and Ethnicity in Determining HIV Risk Perception and Willingness to Undergo HIV Testing Among Rural Women in Burkina Faso," vol. 9, no. 2, 2005.

[17] A. J. Ross and P. O. Ocholla, "Correlation between knowledge of HIV, attitudes and perceptions of HIV and a willingness to test for HIV at a regional hospital in KwaZulu-Natal, South Africa," pp. 1-8, 2012.

[18] L. Yuan et al., "Factors associated with willingness to participate in free HIV test among general residents in Heilongjiang, Northeast China," pp. 2-9, 2012. 